\title{
Desempenho de bovinos jovens alimentados com dietas contendo grão úmido de milho ou sorgo ${ }^{1}$
}

\section{Mauricio Scoton Igarasi ${ }^{2}$, Mário de Beni Arrigoni ${ }^{3}$, André Alves de Souza ${ }^{2}$, Antonio Carlos Silveira $^{3}$, Cyntia Ludovico Martins ${ }^{3}$, Henrique Nunes de Oliveira ${ }^{3}$}

\author{
${ }^{1}$ Bolsa concedida pela CAPES. \\ 2 Programa de Pós-graduação em Zootecnia. \\ ${ }^{3}$ Departamento de Melhoramento e Nutrição Animal - FMVZ/UNESP, Botucatu, SP.
}

RESUMO - Objetivou-se com este estudo verificar diferenças no desempenho de animais jovens alimentados com dietas contendo grão úmido de milho ou sorgo. Utilizaram-se dois tratamentos experimentais, nos quais a dieta total possuía, como ingrediente energético principal, grão úmido de milho (TMU) ou grão úmido de sorgo (TSU). Noventa novilhos inteiros F1 Red Angus $\times$ Nelore, com 8 meses de idade e $240 \mathrm{~kg}$ de peso vivo médio inicial, foram alimentados durante 172 dias e divididos nos dois tratamentos, segundo delineamento inteiramente casualizado. Não foi verificada diferença para ganho de peso diário, ganho de peso total e peso final de abate. Com relação à carcaça, a área de olho-de-lombo, a espessura de gordura subcutânea e a espessura de gordura na garupa também não diferiram estatisticamente entre os tratamentos. Concluiu-se que a substituição integral do TMU pelo TSU não alterou o desempenho de bovinos jovens em confinamento.

Palavras-chave: Nelore, nutrição, Red Angus, ruminantes, silagem, superprecoce

\section{Performance of young cattle fed diets with high moisture corn or sorghum}

\begin{abstract}
The differences on performance of young cattle fed diets with high moisture corn or sorghum were evaluated in two treatments, where the main energy source of the total diet was composed of high moisture corn (HMC) or sorghum (HMS). Ninety Angus $\times$ Nelore crossbred young bulls, averaging 8 month of age and $240 \mathrm{~kg}$ BW and fed during 172 days were allotted to two experimental treatments as a completely randomized design. No treatment effect on average daily gain, total weight gain and slaughter final weight was observed. Regarding the carcass, ribeye area, subcutaneous fat thickness and rump fat thickness also did not differ between treatments. In conclusion, the totally replacement of high moisture corn by high moisture sorghum did not affect performance of feedlot young cattle.
\end{abstract}

Key Words: Nelore, nutrition, Red Angus, ruminant, silage, young cattle

\section{Introdução}

A maior eficiência na conversão de alimento em carne em animais jovens é citada por diversos autores (Myers et al., 1999; Schoonmaker et al., 2002a, b), sendo resultado dos menores requerimentos energéticos de mantença, o que proporciona maior direcionamento da energia para ganho de peso (NRC, 1996). A eficiência de ganho de peso e as características de carcaça são os maiores determinantes da eficiência de sistemas de produção de carne bovina.

Ressaltando a importância da manipulação de fontes energéticas na nutrição animal, a fim de obter otimização entre eficiência biológica e econômica, verifica-se que as fontes de amido mais comumente utilizadas são os grãos de cereais, especialmente o milho e o sorgo, nos quais o amido representa aproximadamente $70 \%$ da matéria seca MS (Rooney \& Pflugfelder, 1986). Schoonmaker et al. (2002a) discutiram que os sistemas produtivos de bovinos jovens inteiros sob dietas de alta densidade energética, ou seja, dietas de alto grão possibilitaram excelentes resultados no desempenho e nas características de carcaça.

Jobim \& Reis (2001) descreveram que os grãos de milho, mesmo quando triturados ou parcialmente quebrados, são protegidos pelo pericarpo, o qual é muito resistente à degradação microbiana e à digestão enzimática no intestino delgado. Estudos com silagem de grãos úmidos de milho constataram aumento na digestibilidade da matéria orgânica, principalmente em razão do aumento na digestão do amido, o que torna a ensilagem de grãos úmidos uma 
notável alternativa na estratégia nutricional para a alimentação animal (Huntington, 1997).

Além da considerável melhoria no desempenho animal, a silagem de grãos úmidos representa interessantes vantagens agronômicas, como antecipação da colheita em cerca de 30 dias (otimização do uso da terra) e redução nas perdas no campo (fatores climáticos, ataque de insetos e pássaros predadores) e nas perdas qualitativas e quantitativas do grão durante a armazenagem (Costa et al., 1999).

A silagem de grão úmido pode ser definida como o produto da conservação em meio anaeróbio de sementes ou grãos de cereais logo após a maturação fisiológica, com teor de umidade em torno de 28\%, na amplitude de 25 a 30\%. O processo de fermentação da ensilagem de grãos com alta umidade tem como princípio a fermentação bacteriana, destacando-se o nível de oxigênio (anaerobiose), a concentração de carboidratos solúveis, a umidade e a população microbiana como características que afetam o processo (Costa et al., 1999).

O grão úmido deve ser colhido quando atingir a maturidade fisiológica, momento em que não ocorre mais depósito de nutrientes no grão e este atingiu maior peso seco. O milho alcança esse estado fisiológico em torno de 30 a $35 \%$ de umidade no grão e o sorgo, de 25 a 30\%, segundo Clark (1988). Jobim \& Reis (2001) relataram que o ponto ideal para a colheita do milho será quando o grão apresentar entre 32 e 35\% de umidade, em torno de 50 dias após a polinização, momento em que a espiga apresenta brácteas secas e a formação de uma lâmina preta na base do grão.

O processamento de grãos úmidos de milho e sorgo através da ensilagem promove alterações químicas e físicas nas moléculas do amido, facilitando a ação das enzimas amilolíticas na digestão microbiana e das enzimas pancreáticas na digestão que ocorre no intestino delgado (Owens et al., 1997).

O aumento da degradabilidade ruminal do amido tem-se mostrado vantajoso no sentido de maximizar a capacidade fermentativa do rúmen, elevando a síntese da proteína microbiana e a produção de ácidos graxos voláteis, particularmente do ácido propiônico, o principal precursor gluconeogênico em ruminantes (Rooney \& Pflugfelder, 1986). O resultado final pode ser o maior fluxo líquido de energia na veia porta, aumento na síntese de glucose pelo fígado e maior disponibilidade de aminoácidos para síntese da proteína muscular (Theurer et al., 1995).

Ladely et al. (1995) trabalharam com diferentes dietas para novilhos em terminação, observando menor consumo de MS, maior ganho de peso e, portanto, maior conversão alimentar quando os animais foram alimentados com silagem de milho úmido em relação aos alimentados com grão seco laminado. Hibberd et al. (1985) observaram aumento significativo na digestibilidade da proteína quando grãos úmidos de milho ou de sorgo substituíram grãos secos moídos nas dietas de novilhos em crescimento.

O grão úmido de sorgo também apresenta elevação na digestibilidade. Em experimento com novilhos canulados no duodeno e no íleo, Hill et al. (1991) verificaram maior digestibilidade ruminal e total do grão de sorgo úmido quando comparado ao grão de sorgo seco.

A utilização de grãos de sorgo nas dietas de bovinos tem aumentado nos últimos anos, devido, principalmente, aos seus benefícios agronômicos (resistência à seca, fungos e predadores). Muitos produtores não utilizam o grão de sorgo pela sua qualidade variável e seu menor valor nutritivo em relação ao milho. Variações na digestibilidade e, conseqüentemente, no desempenho animal podem ser explicadas parcialmente pelos efeitos de variedade (genótipo) e pelas técnicas de processamento (Hibberd et al., 1985). Dependendo do processamento físico do grão para a alimentação, o sorgo tem apresentado 85 a 100\% do valor nutricional do milho e valor econômico em torno de 90\% do valor do milho, no sistema de produção dos Estados Unidos (Pedersen et al., 2000).

Costa et al. (1999) destacaram que, no Brasil, ainda são escassas as informações no meio científico sobre o uso da silagem de grãos úmidos na alimentação animal, apesar do crescente emprego desta tecnologia no setor produtivo, especialmente de bovinos em sistemas intensivos de produção. Nesse sentido, objetivou-se, com este trabalho, verificar a viabilidade de utilização da silagem de grão úmido de sorgo em substituição total à silagem de grão úmido de milho, na resposta ao desempenho de bovinos jovens em confinamento.

\section{Material e Métodos}

O experimento foi desenvolvido no Confinamento Experimental do Projeto Temático Crescimento de Bovinos de Corte no Modelo Biológico Superprecoce da Faculdade de Medicina Veterinária e Zootecnia, UNESP, campus de Botucatu. Os animais, oriundos de fazenda comercial, foram criados do nascimento à desmama em pastagens cultivadas (Panicum maximun) e receberam suplementação de concentrado no sistema de creepfeeding. Após o desmame, os animais foram confinados em instalações do experimento, sendo identificados e tratados contra endo e ectoparasitas.

Noventa bezerros F1 Red Angus $\times$ Nelore, machos inteiros e desmamados com aproximadamente 210 dias de idade, foram distribuídos aleatoriamente em seis baias 
(10x30 m), com 15 animais em cada uma. Assim, totalizaram-se dois tratamentos com três baias cada.

A colheita do grão úmido de milho e de sorgo foi realizada com uma colheitadeira automotriz e os grãos resultantes, moídos e acondicionados em silos tipo "bag”. O milho (híbrido 333B - Dekalb) foi colhido no estádio de maturação fisiológica e o sorgo (híbrido 3KB58 - Dekalb), com aproximadamente $70 \%$ de MS nos grãos.

Os tratamentos foram constituídos por dieta total com silagem de grão úmido de milho, como ingrediente energético principal (TMU), e dieta total com silagem de grão úmido de sorgo, como ingrediente energético principal (TSU). As dietas foram formuladas com a utilização do Software CNCPS versão 4.0 (CNCPS, 2000), de modo a serem isoenergéticas e isoprotéicas para os tratamentos experimentais, objetivando-se ganho de $1,4 \mathrm{~kg} \cdot \mathrm{dia}^{-1}$ (Tabela 1).

$\mathrm{O}$ premix foi formulado para atender às exigências mineral e protéica dos animais (Tabela 2). A composição química-bromatológica dos ingredientes constituintes da dieta está apresentada na Tabela 3.

Os animais receberam ração total ad libitum, fornecida duas vezes ao dia, às 9 e $16 \mathrm{~h}$. O consumo da dieta foi mensurado pela pesagem do alimento fornecido diariamente, sendo calculado o total fornecido a partir de uma

Tabela 1 - Composição de ingredientes das dietas experimentais TMU e TMS (\% MS)

\begin{tabular}{lcc}
\hline Ingrediente & \multirow{2}{*}{$\mathrm{TU}^{1}$} & $\mathrm{TSU}^{2}$ \\
\hline Feno Cynodon sp & & $\%$ \\
Silagem de milho & 21,00 & 20,00 \\
Grão úmido de milho & 7,00 & 8,00 \\
Grão úmido de sorgo & 44,00 & - \\
Caroço de algodão & - & 45,00 \\
Premix mineral protéico & 10,00 & 10,00 \\
\hline
\end{tabular}

${ }^{1} \mathrm{TMU}=$ tratamento com dieta com grão úmido de milho.

$2 \mathrm{TSU}=$ tratamento com dieta com grão úmido de sorgo.

Tabela 2 - Composição de ingredientes do premix mineral protéico das dietas experimentais (\%MS)

\begin{tabular}{lr}
\hline Ingrediente & $\%$ MS \\
\hline Farelo de algodão & 43,56 \\
Farelo de soja & 29,18 \\
Uréia & 2,92 \\
Calcário & 13,62 \\
Mistura mineral & 10,70 \\
Ionóforo (monensina sódica) & 0,02 \\
\hline
\end{tabular}

análise visual de sobra no cocho, para que não ultrapassasse valores superiores a $5 \%$ do total fornecido diariamente.

Foram coletadas amostras das dietas experimentais fornecidas a cada sete dias, formando uma amostra composta para um período de 28 dias, que foram acondicionadas em sacos plásticos e armazenadas em freezer $\left(-4^{\circ} \mathrm{C}\right)$ para análises posteriores.

$\mathrm{O} \mathrm{pH}$ da silagem foi medido por intermédio de um potenciômetro digital (Digimed TE-902). Os teores de MS, matéria mineral (MM), proteína bruta (PB) e extrato etéreo (EE) foram analisados segundo os protocolos da AOAC (1990), ao passo que os de fibra em detergente neutro (FDN), fibra em detergente ácido (FDA) e lignina, segundo metodologia proposta por Van Soest et al. (1991). A correção de cinzas foi realizada no cálculo de FDN e FDA. Os teores de NDIN e NIDA foram mensurados conforme metodologia proposta por Krishnamoorthy et al. (1982) e os de carboidratos não-fibrosos (CNF) e NDT, pelas fórmulas sugeridas por Weiss (NRC, 2001).

O período experimental foi de 172 dias, em que os 40 primeiros foram destinados à adaptação dos animais às dietas experimentais. A avaliação do desempenho animal (ganho de peso diário - GPD, ganho de peso total - GP e peso final - PF) foi realizada com a efetuação de pesagens em intervalos de 28 dias, sempre antes da primeira refeição do dia (9h) e com jejum alimentar de sólidos de 16 horas. O peso vivo inicial foi obtido após a fase de adaptação.

A avaliação das características de carcaça (área de olho-de-lombo - AOL e espessura de gordura subcutânea - EGS) dos animais foi realizada a partir de imagens obtidas entre a $12^{\underline{a}}$ e $13^{\underline{a}}$ costelas, conforme metodologia descrita por Herring et al. (1994), por um profissional treinado e habilitado. Na ocasião da última pesagem dos animais experimentais, foi mensurada a espessura de gordura na altura garupa do animal (picanha, junção entre Bíceps femoris e gluteos medius). Foi utilizado o aparelho de ultra-sonografia veterinária PIE MEDICAL Scanner 200, com uma sonda linear de 17,2 cm e 3,5 MHz (Sector Curved Array Scanner, modelo 51B04UM02). As imagens foram analisadas em softwares específicos para o aparelho (PIE MEDICAL, Inc.)

$\mathrm{O}$ experimento caracterizou-se em um delineamento inteiramente casualizado, com dois tratamentos (TMU e TSU) e 45 repetições por tratamento. Cada animal correspondeu a uma unidade experimental. A análise dos dados obtidos das diversas variáveis foi realizada pelo procedimento GLM (General Linear Model) (SAS, 1998). Utilizou-se o teste Tukey para comparação das médias 
Tabela 3 - Composição nutricional dos ingredientes e das dietas experimentais

\begin{tabular}{|c|c|c|c|c|c|c|c|}
\hline Item $^{1}$ & $\begin{array}{l}\text { Premix mineral } \\
\text { protéico }\end{array}$ & $\begin{array}{l}\text { Grão úmido de } \\
\text { milho }\end{array}$ & $\begin{array}{l}\text { Grão úmido de } \\
\text { sorgo }\end{array}$ & $\begin{array}{l}\text { Silagem de } \\
\text { milho }\end{array}$ & Feno de Cynodon sp & TMU & TSU \\
\hline MS, \% & 92,00 & 66,42 & 61,48 & 49,26 & 80,83 & 64,13 & 63,42 \\
\hline $\mathrm{pH}$ & - & 4,63 & 4,68 & 4,50 & - & - & - \\
\hline CNF, \% MS & 11,59 & 74,51 & 76,55 & 36,53 & 15,41 & 44,60 & 44,76 \\
\hline PB, \% MS & 41,25 & 10,01 & 9,66 & 8,15 & 4,83 & 15,97 & 14,84 \\
\hline EE, \% MS & 1,72 & 5,15 & 3,93 & 4,26 & 2,13 & 6,19 & 4,88 \\
\hline FDN, \% MS & 11,34 & 9,63 & 8,22 & 46,94 & 74,20 & 26,46 & 28,15 \\
\hline FDA, \% MS & 9,62 & 3,40 & 5,00 & 28,76 & 42,93 & 14,34 & 15,09 \\
\hline Lignina, \% MS & 3,35 & 0,55 & 1,13 & 4,76 & 6,70 & 3,49 & 3,64 \\
\hline NDIN, \% $\mathrm{N}$ total & 2,89 & 3,82 & 6,91 & 18,79 & 37,99 & 7,45 & 9,47 \\
\hline NIDA, \% $\mathrm{N}$ total & 2,85 & 1,67 & 3,97 & 6,79 & 22,56 & 5,22 & 7,72 \\
\hline MM, \% MS & 34,10 & 0,71 & 1,63 & 4,12 & 3,43 & 6,78 & 7,37 \\
\hline NDT, \% MS & 55,65 & 90,30 & 89,24 & 62,35 & 54,37 & 73,59 & 70,21 \\
\hline
\end{tabular}

${ }^{1} \mathrm{CNF}=$ carboidratos não-fibrosos; NDIN = nitrogênio insolúvel em detergente neutro; NIDA = nitrogênio insolúvel em detergente ácido; MM = matéria mineral

2 TMU = tratamento com dieta com grão úmido de milho.

${ }^{3} \mathrm{TSU}=$ tratamento com dieta com grão úmido de sorgo.

entre as causas de variação, adotando-se nível de significância de 5\%.

\section{Resultados e Discussão}

Comparando-se a densidade energética dos dois grãos de cereais ensilados sob alta umidade, verificou-se que o sorgo obteve $98,8 \%$ do NDT do milho (Tabela 3). Os valores obtidos neste experimento corroboram os verificados por Huck et al. (1999), sendo que a silagem de grão úmido de sorgo apresentou $96 \%$ da energia líquida para ganho de peso do milho floculado, de 1,60 e 1,68 Mcal/kg, respectivamente. Resultados semelhantes foram apresentados por Rooney \& Pflugfelder (1986), sendo que várias pesquisas indicam que o sorgo apresenta valor nutricional de 93 a 96\% em comparação ao do milho.

O desempenho animal não foi influenciado estatisticamente pelos tratamentos com diferentes ingredientes energéticos da dieta (milho ou sorgo), uma vez que as variáveis peso vivo final (PVF), ganho de peso diário (GPD), AOL, EGS e espessura de gordura na garupa (EGG) não apresentaram diferença $(\mathrm{P}>0,05)$ entre os tratamentos (Tabela 4). Resultados semelhantes foram obtidos por Passini et al. (2003), que, avaliando a terminação de novilhos superprecoces sob dietas à base de ingredientes energéticos de silagem de grão úmido de sorgo ou grão seco de milho, também não verificaram diferença no GPD, PVF, na EGS e AOL.

Huck et al. (1999) também não verificaram diferença no desempenho e nas características de carcaça de novilhas alimentadas com silagem de grão úmido de sorgo a 35\% de umidade e milho floculado, quando fornecidos em iguais proporções da dieta total ( $78 \%$ da MS total da dieta). Segundo esses autores, a umidade do grão entre 30 e 35\% acarretou melhoria no processo fermentativo, com aumento na produção de ácido láctico, proporcionando redução mais acentuada no $\mathrm{pH}$. Houve também aumento de $6 \%$ na eficiência de ganho, quando se elevou a umidade de 25 para $35 \%$ na ensilagem do grão de sorgo, devido, principalmente, à maior disponibilidade do amido às enzimas amilolíticas .

Theurer (1986), sumarizando vários trabalhos com diferentes formas de processamento do grão de cereais, verificou maior digestibilidade ruminal para o amido proveniente do milho ( 7 a 9 pontos percentuais) em relação ao amido proveniente do sorgo. Analisando-se os dados de digestibilidade in vitro de Pedersen et al. (2000), nota-se que o sorgo seco apresentou digestibilidade da MS e do amido 14,3 e 15,6\% inferiores em relação ao grão seco de milho, respectivamente. Também trabalhando com silagem de grãos de alta umidade, Huntington (1997) verificou valores para a digestibilidade ruminal do amido do milho e sorgo de 89,9 e 73,2\%, respectivamente, sendo o sorgo 18,6\% menos degradado no rúmen que o milho.

Galyean et al. (1976) obtiveram valor de digestibilidade ruminal de 89,3\% para o amido da silagem de grão úmido de milho, enquanto Nocek \& Taminga (1991), de 86,2\% para silagem de grão úmido de sorgo e entre 83 e $89 \%$ para silagem de grão úmido de milho. Passini et al. (2003) encontraram valor de digestibilidade total da MS de 93,58 e 96,71\%, respectivamente, para a silagem de grão úmido de milho e a silagem de grão úmido de sorgo. Com base na revisão de trabalhos citados na literatura, infere-se que a degradabilidade do grão úmido de sorgo situa-se entre +3 e -20\% em relação à degradabilidade do grão úmido de milho (Theurer, 1986; Huntington, 1997; Pedersen et al, 2000; Passini, 2001).

Considerando-se menor degradabilidade ruminal para o sorgo em relação ao milho, esperar-se-ia maior quantidade de grão de sorgo digerido pós-rúmen, principalmente no 
Tabela 4 - Parâmetros da carcaça e características de desempenho animal

\begin{tabular}{|c|c|c|c|c|}
\hline Característica & TMU & TSU & $\mathrm{CV}^{1}(\%)$ & Valor $\mathrm{P}$ \\
\hline Ganho de peso diário, kg & 1,41 & 1,43 & 13,20 & 0,64 \\
\hline Peso final, kg & 482,54 & 486,81 & 4,86 & 0,40 \\
\hline Espessura de gordura subcutânea inicial, mm & 1,92 & 2,02 & - & - \\
\hline Área de olho-de-lombo inicial, $\mathrm{cm}^{2}$ & 51,29 & 51,64 & - & - \\
\hline Espessura de gordura subcutânea final, mm & 4,28 & 4,16 & 21,69 & 0,54 \\
\hline
\end{tabular}

${ }^{1}$ Coeficiente de variação (\%).

intestino delgado, o que pode explicar resultados de desempenho semelhantes entre os dois tratamentos testados neste trabalho. O questionamento sobre a eficiência da digestão intestinal do amido foi amplamente discutido na década de 80, destacando-se como fatores limitantes a quantidade de enzimas (Orskov, 1986) ou a superfície para a atuação enzimática e o tempo de passagem da digesta pelo trato digestivo (Owens et al., 1986). Contudo, Hill et al. (1991) verificaram que maiores quantidades de amido atingindo o intestino delgado ocasionaram aumento na digestão intestinal do amido, promovendo correlação linear positiva nessas duas variáveis $\left(r^{2}=0,99\right)$. A mesma correlação foi verificada no intestino grosso $\left(r^{2}=0,71\right)$.

Richards et al. (2002) verificaram que, em ruminantes alimentados com dietas em que alta quantidade de amido atingiu o duodeno, aumentou-se a quantidade de amido desaparecido pós-rúmen, uma vez fornecida proteína simultaneamente para o intestino delgado. Concordando, Hibberd et al. (1985) descreveram que aumentos na digestão de amido no intestino delgado são possíveis com o fornecimento adequado de proteína metabolizável. Esses autores relataram que maiores teores de proteína metabolizável atingindo o duodeno promovem maior liberação de enzimas amilolíticas, elevando a digestão intestinal de amido. As dietas experimentais utilizadas apresentaram valores de proteína metabolizável suficientes para ganho de peso de 1,92 e 1,79 kg.dia-1, para os tratamentos experimentais TMU e TSU, respectivamente. Assim, o teor de proteína metabolizável nas dietas pode ter possibilitado a digestão de elevadas quantidades de amido no intestino.

A literatura cita alta digestibilidade intestinal e total para a silagem de grão úmido de sorgo. Em sua revisão, Huntington (1997) sumarizou digestibilidade intestinal do amido de $46 \%$ e total de $92,8 \%$, considerando-se o grão úmido de sorgo. Hibberd et al. (1985), trabalhando com grão de sorgo reconstituído (grão seco ensilado com acréscimo de água até atingir 30\% de umidade), sendo duas varieda- des em relação ao teor de tanino, verificaram que 67,5 e $70,9 \%$ do amido que atingiu o intestino delgado foi digerido nesse sítio, enquanto 94,8 e 98,4\% do amido consumido foi digerido no trato total, respectivamente, para a variedade de alto e baixo tanino. Os autores também verificaram que $95,2 \%$ do tanino foram degradados no rúmen.

Geralmente, o processamento de grãos é associado a aumento na eficiência de utilização de nutrientes pelos microrganismos ruminais e no trato total (Nocek \& Taminga, 1991). Contudo, caso grande parte do amido seja digerido no rúmen, menores quantidades absolutas serão digeridas na porção pós-rúmen, devido à reduzida quantidade de digesta potencialmente digestível deixando o rúmen (Richards et al., 2002). Assim, materiais com menor degradabilidade ruminal, mas potencialmente digestíveis na porção intestinal, como o caso da silagem de grão úmido de sorgo, podem ser digeridos em maiores quantidades no intestino, em razão da maior quantidade de amido escoando pós-rúmen (Nocek \& Taminga, 1991). Esses autores encontraram correlação significativa $(\mathrm{P}<0,001)$, de 0,82 , entre a elevação da quantidade de amido escapando do rúmen e a quantidade de amido digerida nos intestinos.

Outra questão que envolve a eficiência da digestão intestinal do amido é o consumo de glicose pelo metabolismo dos tecidos viscerais (PDV, portal drain viscera). O fluxo líquido de glicose na veia porta, que é a diferença entre absorção de glicose pelo intestino e o gasto de glicose pelos tecidos vicerais, reflete em ganhos no desempenho animal. Na revisão de Nocek \& Taminga (1991), nota-se que a energia metabolizável utilizada pelo PDV em novilhas foi superior em dietas com maior teor de volumoso do que em dietas com maior teor de concentrado, tendo o custo da energia de mantença aumentado em mais de 50\%, em decorrência do metabolismo digestivo. Wheighart et al. (1986) realizaram uma análise de regressão e verificaram fluxo líquido positivo de glicose na veia porta (pós PDV), quando o consumo diário de energia digestível foi superior a 23 Mcal. Nesse sentido, 
infere-se que, em algumas dietas de alto concentrado, assim como as deste experimento (Tabela 3), poderia ter ocorrido menor consumo de glicose pelos tecidos viscerais, promovendo maior desempenho dos animais.

O processamento de grão de cereais tem sido reportado como o responsável pelo aumento no desempenho animal (Galyean et al., 1979; Zinn et al., 2002), devido à elevação da energia líquida da dieta (NRC, 1996). Entretanto, Fulton et al. (1979) constataram que aumentos na degradabilidade ruminal do amido de cereais, graças ao seu processamento, podem ser não compensadores, em razão da excessiva produção de ácidos graxos no rúmen, retratando uma situação de acidose subclínica, o que pode resultar em desempenhos similares entre animais alimentados com dietas com diferentes níveis de processamento de grãos. Gorocica-Buenfil \& Loerch (2005), alimentando animais jovens em confinamento com milho moído finamente ou grão inteiro, verificaram que o processamento do grão não promoveu benefícios adicionais, sendo que o ganho de peso, a eficiência alimentar e as características de carcaças não foram alterados, devido, provavelmente, a distúrbios ruminais.

Nesse mesmo sentido, a utilização conjunta de fontes de amido com diferentes degradabilidades apresenta efeito associativo pela diminuição do risco do quadro de acidose subclínica, promovida pela dieta de ruminantes com alta concentração de grãos (Stock et al., 1991; GorocicaBuenfil \& Loerch, 2005). Mendonza et al. (1998) citaram que, na Universidade de Nebraska, nove estudos realizados com a utilização combinada de grão úmido de milho (67 a $75 \%$ da dieta) e grão de sorgo laminado (33 a $25 \%$ ), resultaram em ganho de peso $2,7 \%$ superior e $4,6 \%$ mais eficiente que a média obtida nos animais alimentados com os dois grãos isolados, devido, possivelmente, ao efeito associativo da utilização de fontes de amido de diferentes degradabilidades ruminais.

A menor degradabilidade ruminal da silagem de grão úmido de sorgo, em comparação à silagem de grão úmido de milho, provavelmente foi compensada pelos benefícios obtidos com a diminuição dos riscos de distúrbios ruminais e o aumento na digestão intestinal. A explicação da similaridade em desempenho animal entre as duas dietas experimentais não é totalmente clara, sendo provavelmente o resultado de interações características do amido $\times$ digestão pós-rúmen $\times$ acidose subclínica.

\section{Conclusões}

A utilização de grão úmido de sorgo, em relação ao grão úmido de milho, como principal ingrediente energético da dieta, não alterou o desempenho de bovinos jovens, em confinamento, alimentados com dieta de alto grão.

\section{Literatura Citada}

ASSOCIATION OF OFFICIAL ANALYTICAL CHEMISTS - AOAC. Official methods of analysis. 15.ed. Arlington: 1990. v.1, $1117 \mathrm{p}$.

CLARK, J. Managing high moisture and reconstituted grains. In: MC CUllough, K.K.; BOLSEN, M.E. (Eds.) Silage management. Des Miones: Silage Technology Division National Feed Ingredients Association, 1988. p.205-230.

CORNELL NET CARBOHYDRATE AND PROTEIN SYSTEM CNCPC. The net carbohydrate and protein system for evaluating herd nutrition and nutrients excretion. Version 4.0. Ithaca: 2000. 237p.

COSTA, C.; ARRIGONI, M.B.; SILVEIRA, A.C. et al. Silagem de grãos úmidos. In: SIMPÓSIO SOBRE NUTRIÇÃO DE BOVINOS, 7., 1999, Piracicaba. Anais... Piracicaba: Fundação de Estudos Agrários Luiz de Queiroz, 1999. p.69-87.

FULTON, W.R.; KLOPFENSTEIN, R.A.; BRITTON, R.A. Adaptation to high concentrate diets by beef cattle.I. Adaptation to corn and wheat diets. Journal of Animal Science, v.49, p.775-784, 1979.

GALYEAN, M.L.; WAGNER, D.G.; JONSON, R.R. Site and extent of starch digestion in steers fed processed corn rations. Journal of Animal Science, v.43, p.1088-1094, 1976.

GALYEAN, M.L.; WAGNER, D.G.; OWENS, F.N. Corn particle size and site and extent of digestion by steers. Journal of Animal Science, v.49, p.204-110, 1979.

GOROCICA-BUENFIL, M.A.; LOERCH, S.C. Effect of cattle age, forage level, and corn processing on the diet digestibility and feedlot performance. Journal of Animal Science, v.83, p.705714, 2005.

HERRING, W.O.; WILLIAMS, S.E.; BERTRAND, J.K. et al. Comparison of live and carcass equations predicting percentage of cutability, retail products weight, and trimmable fat in beef cattle. Journal of Animal Science, v.72, p.1107-1118, 1994

HIBBERD, C.A.; WAGNER, D.G.; HINTZ, R.L. et al. Effect of sorghum grain variety and reconstitution on site and extent of starch and protein digestion in steers. Journal of Animal Science, v.61, p.702-712, 1985.

HILL, T.M.; SCHMIDT, S.P.; RUSSEL, R.W. et al. Comparison of urea treatment with established methods of sourghum grain preservation and processing on site and extend of starch digestion by cattle. Journal of Animal Science, v.69, p.45704576, 1991.

HUCK, G.L.; KREIKEMEIER, K.K.; BOLSEN, K.K. Effects of reconstituting fiel dried and early harvested sorghum grain on the ensiling characteristics of the grain and growth performance and carcass merit of feedlot cattle. Journal of Animal Science, v.77, p.1074-1081, 1999.

HUCK, G.L.; KREIKEMEIER, K.K.; KUHL, G.L. et al. Effects of feeding combinations of steam-flaked, high-moisture, or dry rolled corn on growth performance and carcass characteristics in feedlot cattle. Journal of Animal Science, v.76, p.29842990, 1998.

HUNTINGTON, G.B. Starch utilization by ruminants. From basics to the brink. Journal of Animal Science, v.75, n.3, p.852 $867,1997$.

JOBIM, C.C.; REIS, R.A. Produção e utilização de silagem de grãos úmidos de milho. Workshop sobre silagem. In: REUNIÃO ANUAL DA SOCIEDADE BRASILEIRA DE ZOOTECNIA, 38. 2001, Piracicaba. Anais... Piracicaba: Sociedade Brasileira de Zootecnia, 2001. p.912-927.

KRISHNAMOORTHY, U.C.; MUSCATO, T.V.; SNIFFEN, C.J. et al. Nitrogen fraction in selected feedstuffs. Journal of Dairy Science, v.65, n.1, p.217-225, 1982. 
LADELY, S.R.; STOCK, R.A.; GOEDEKEN, F.K. et al. Effect of corn hybrid and grain processing method on rate of starch disappearance and performance of finish cattle. Journal of Animal Science, v.73, p.360-364, 1995.

MENDONZA, G.D.; BRITTON, R.A.; STOCK, R.A. Ruminal fermentation and in situ starch digestion with high moisture corn, dry rolled grain sorghum or a mixture these grains. Feed Science and Technology, v.74, p.329-335, 1998.

MYERS, S.E.; FAULKNER, D.B.; IRLAND, F.A. et al. Production systems comparing early weaning to normal weaning with or without creep feeding for beef steers. Journal of Animal Science, v.77, p.300-310, 1999.

NATIONAL RESEARCH COUNCIL - NRC. Nutrient requirements of beef cattle. 7.ed. Washington, D.C.: National Academy of Science, 1996. 242p.

NATIONAL RESEARCH COUNCIL - NRC. Nutrient requirements of dairy cattle. 8.ed. Washington, D.C.: National Academy of Science, 2001. 408p.

NOCEK, J.E.; TAMMINGA, S. Site of digestion of starch in the gastrointestinal tract of dairy cows and it effect on milk and composition. Journal of Dairy Science, v.74, p.3598-3629, 1991.

ORSKOV, E.R. Starch digestion and utilization in ruminants. Journal of Animal Science, v.63, p.1624-1633, 1986.

OWENS, F.N.; SECRISTI, D.S.; JEFF HILL, W. et al. The effect of grain source and grain processing on performance of feedlot cattle: a review. Journal of Animal Science, v.75, p.868879, 1997.

OWENS, F.N.; ZINN, R.A.; KIM, Y.K. Limits to starch digestion in the ruminant small intestine. Journal of Animal Science, v.63, p.1634-1648, 1986.

PASSINI, R.; RODRIGUES, P.H.M.; CASTRO, A.L. et al. Parâmetros de fermentação ruminal em bovinos alimentados com grãos de milho ou sorgo de alta umidade. Revista Brasileira de Zootecnia, v.32, n.5, p.1266-1274, 2003.

PEDERSEN, J.F.; MILTON, T.; MASS, R.A. A twelve-hour in vitro procedure for sorghum grain feed quality assessment. Crop Science, v.40, p.204-208, 2000.

POORE, M.H.; ECK, T.P.; SWINGLE, R.S. et al. Total starch and relative starch availability of feed grains. In: BIENAL CONFERENCE ON RUMEN FUNCTION, 1989, Chicago. Proceedings... Chicago, 1989. v.20, p.35. (Abstract).
RICHARDS, C.J.; BRANCO, A.F.; BOHNER, D.W. et al. Intestinal starch disappearance increased in steers abomasally infused with starch and protein. Journal of Animal Science, v.80, p.33613368, 2002.

ROONEY, L.W.; PFLUGFELDER, R.L. Factors affecting digestibility with special emphasis on sorghum and corn. Journal of Animal Science, v.63, p.1607-1623, 1986.

SCHOONMAKER, J.P.; LOERCH, S.C.; FLUHARTY, F.L. et al. Effect of age at feedlot entry on performance carcass characteristics of bulls and steers. Journal of Animal Science, v.80, p.2247-2254, 2002b.

SCHOONMAKER, J.P.; LOERCH, S.C.; FLUHARTY, F.L. et al. Effect of an accelerated finish program on performance, carcass characteristics, and circulant insulin-like growth factor-I concentration of early-weaned bulls and steers. Journal of Animal Science, v.80, p.900-910, 2002a.

STATISTICAL ANALYSIS SYSTEM - SAS. SAS/STAT: user's guide (release 6.10). version 6.12, 4.ed. Cary: SAS Institute, 1998. 842p.

STOCK, R.A.; BRITTON, R.A.; SINDT, M.H. et al. High moisture corn utilization in finishing cattle. Journal of Animal Science, v.69, p.1645-1656, 1991.

THEURER, C.B. Grain processing effects on starch utilization by ruminants. Journal of Animal Science, v.63, p.1649-1662, 1986.

THEURER, C.B.; HUBER, J.T.; SANTOS, F.A.P. Feeding and managing for maximal milk protein. In: SOUTHWEST NUTRITION AND MANAGEMENT CONFERENCE, 1995, Ahwatukee. Proceedings... Ahwatukee: University of Arizona, 1995. p.59.

Van SOEST, P.J.; ROBERTSON, J.B.; LEWIS, B.A. Methods for dietary fiber, neutral detergent fiber, and nonstarch polysaccharides in relation to animal nutrition. Journal of Dairy Science, v.74, n.10, p.3583-3597, 1991.

WEIGHART, M.; SLEPTIS, R.; ELLIOT, J.M. Glucose absorption and hepatic gluconeogenesis in dairy cows fed diets varying in forage content. Journal of Nutrition, v.116, p.839-850, 1986.

ZINN, R.A.; OWENS, F.N.; WARE, R.A. Flaking corn: processing mechanics, quality standarts, and impacts on energy availability and performance in feedlot cattle. Journal of Dairy Science, v.80, p.1145-1156, 2002. 